\title{
Sensitivity of Penicillium digitatum and $P$. italicum to Postharvest Citrus Fungicides in California
}

\author{
Gerald J. Holmes and Joseph W. Eckert
}

First author: Department of Plant Pathology, North Carolina State University, Raleigh 27695; and second author: Department of Plant Pathology, University of California, Riverside 92521.

Accepted for publication 24 May 1999.

\begin{abstract}
Holmes, G. J., and Eckert, J. W. 1999. Sensitivity of Penicillium digitatum and P. italicum to postharvest citrus fungicides in California. Phytopathology 89:716-721.

Penicillium digitatum isolates (326), collected in California citrus groves and packinghouses, were assayed qualitatively for their sensitivity to imazalil, thiabendazole, and $o$-phenylphenol. Eighteen typical triple-resistant isolates, acquired in each of 3 years (1988, 1990, and 1994), were assayed quantitatively for their sensitivity to each of the three fungicides. No significant differences were found in the mean sensitivity of the isolates collected in different years. However, the proportion of isolates that were resistant to all three fungicides increased from $43 \%$ in 1988 to $77 \%$ in 1990 and $74 \%$ in 1994. Imazalil-resistant biotypes of $P$. digitatum were isolated
\end{abstract}

ABSTRACT frequently in California packinghouses, while resistant $P$. italicum was rare. No fungicide-resistant biotypes of either species were collected from citrus groves. Wild-type $P$. italicum was slightly less sensitive than wild-type $P$. digitatum to all three fungicides. The concentration of imazalil producing $50 \%$ growth inhibition $\left(\mathrm{EC}_{50}\right)$ was three times greater when the age of the $P$. digitatum assay inoculum was increased from 12 to $24 \mathrm{~h}$. Activity of imazalil increased with $\mathrm{pH}$ of the assay medium in the range $\mathrm{pH} 5.1$ to 5.9 , reflecting the greater concentration of dissociated imazalil at the higher $\mathrm{pH}$ value.

Additional keywords: demethylation inhibitor, fungicide resistance, sterol inhibitor.
Green mold (caused by Penicillium digitatum (Pers.:Fr.) Sacc.) and blue mold ( $P$. italicum Wehmer) are the most important postharvest diseases of citrus fruits produced in California. These wound-obligate pathogens have a relatively short disease cycle ( 3 to 5 days at $25^{\circ} \mathrm{C}$ ) and, on a single fruit, can produce 1 to 2 billion conidia that are efficiently dispersed via air currents (19).

In most California packinghouses, citrus fruits are treated with sodium $o$-phenylphenate (o-phenylphenol), imazalil, and thiabendazole to control Penicillium decay. These fungicides are used in a manner that is highly conducive to the selection and proliferation of resistant biotypes of $P$. digitatum and $P$. italicum. The fruit surface is completely covered by the fungicides, and the residue is persistent for the life of the fruit. Many packinghouses process fruit the year around, resulting in continuous selection pressure on the pathogen population. The common practice of repacking after storage to remove diseased fruit results in efficient aerial dispersal of conidia of fungicide-resistant biotypes to recently harvested fruit being processed in the same packinghouse.

$o$-Phenylphenol and thiabendazole have been used routinely on citrus fruits over the past 3 decades, resulting in a serious problem of resistance to these two fungicides by the late 1970 s $(16,17)$. In 1976, Harding (18) recognized that imazalil, successfully used in Mediterranean citrus production areas for several years, could be an effective treatment for control of thiabendazole-resistant isolates of $P$. digitatum and $P$. italicum in California packinghouses. Imazalil was enthusiastically adopted by the California citrus industry in 1981 as an additive to fruit coating formulations to re-

Corresponding author: G. J. Holmes; E-mail address: gerald_holmes@ncsu.edu

Mention of trade names or commercial products does not constitute endorsement or recommendation for use.

Publication no. P-1999-0719-01R

(C) 1999 The American Phytopathological Society place thiabendazole, which was largely ineffective due to the large population of thiabendazole-resistant Penicillium spp. in California packinghouses.

Despite earlier speculation that fungicide resistance would not become a problem with sterol demethylation inhibitors (12), imazalilresistant biotypes of $P$. digitatum were reported in 1987 (10), just 5 years after the introduction of imazalil as a commercial treatment in California packinghouses. The wide distribution of these isolates in California was confirmed (5), and their potential impact on decay control was demonstrated in commercial packinghouse trials (11).

Although the existence of biotypes of $P$. digitatum and $P$. italicum resistant to $o$-phenylphenol, thiabendazole, or imazalil has been documented in California $(5,10,11,17)$, other citrus production areas $(9,24,27,35)$, and terminal markets $(4)$, the degree and multiplicity of resistance has not. This investigation was undertaken to characterize, both qualitatively and quantitatively, resistance of $P$. digitatum and $P$. italicum in California to imazalil, thiabendazole, and $o$ phenylphenol and to determine if resistance patterns have changed between 1988 and 1994, a 6-year period following the first detection of imazalil resistance in $P$. digitatum (10).

\section{MATERIALS AND METHODS}

Origin, qualitative sensitivity, and storage of Penicillium isolates. Isolates of $P$. digitatum (326) and P. italicum (192) were collected from the atmosphere and from diseased fruit in 30 citrus groves and 26 packinghouses in California between 1986 and 1994. These isolates were evaluated for fungicide sensitivity in comparison with reference isolates from our culture collection.

Isolates were collected from the atmosphere by exposing petri dishes containing Harding's medium $(\mathrm{H}-25$; potato-dextrose agar [PDA, Difco Laboratories, Detroit] plus $2 \mathrm{~g}$ of neopeptone per liter and $2 \mathrm{~g}$ of yeast extract per liter) (17) amended with imazalil (1-[2(2,4-dichlorophenyl)-2-(2-propenyloxy)ethyl]- $1 H$-imidazole; techni- 
cal, $97.5 \%$ a.i.; Janssen Pharmaceutica, Beerse, Belgium) $(0.1 \mu \mathrm{g} / \mathrm{ml})$, thiabendazole (2-[4-thiazolyl] benzimidazole; Freshgard 598, 98.5\% a.i.; FMC BioProducts, Riverside, CA) $(15 \mu \mathrm{g} / \mathrm{ml})$, or $o$-phenylphenol (Dow Chemical, Midland, MI) $(10 \mu \mathrm{g} / \mathrm{ml})$. These fungicide concentrations prevented colony development of wild-type $P$. digitatum and $P$. italicum, but had little or no effect on the growth of fungicide-resistant biotypes.

Conidia were collected from diseased citrus fruits with a sterile, wooden applicator stick that was scored 2 to $3 \mathrm{~cm}$ from the end. The scored end of the stick was used to contact sporulating areas of fruit and then broken off inside a sterile microcentrifuge tube (1.5-ml capacity). A $0.01 \%$ (wt/vol) aqueous Triton X-100 (SigmaAldrich, St. Louis) solution (1 ml) was added to the microcentrifuge tube and vortexed 1 to $2 \mathrm{~s}$ to suspend the conidia. This suspension of conidia was used to inoculate fruit.

Each isolate was inoculated into imazalil-treated and nontreated lemons to confirm its identity and pathogenicity and to determine its qualitative sensitivity to imazalil. Lemons (Citrus limon (L.) N.L. Burman f. 'Eureka') were surface-sterilized in $70 \%$ (vol/vol) aqueous ethanol (1 min) and dipped for $1 \mathrm{~min}$ in imazalil solution $(1 \mathrm{mg} / \mathrm{ml})$ or not treated. Each isolate was injected by hypodermic needle ( $200 \mu \mathrm{l}$ of spore suspension containing $>10^{7}$ conidia per $\mathrm{ml}$ ) into the albedo (i.e., spongy, white endocarp) of three nontreated and three imazalil-treated fruit. The fruit were stored at $15^{\circ} \mathrm{C}$ for 2 to 3 weeks. Imazalil-sensitive isolates decayed imazalil-treated lemons, but did not sporulate on the fruit surface. Imazalil-resistant isolates decayed and sporulated freely on treated fruit.

Of the 326 isolates tested, 186 of those found to be resistant to imazalil were assayed for their resistance to thiabendazole and $o$ phenylphenol. This was determined by streaking spore suspensions ( $>10^{7}$ conidia per $\mathrm{ml}$ ) onto $\mathrm{H}-25$ medium amended with imazalil, thiabendazole, or $o$-phenylphenol as described. Isolates that grew on a fungicide-amended medium were maintained on silica gel at $3^{\circ} \mathrm{C}$ (26). Slant cultures of the above isolates were later obtained by sprinkling a few silica gel crystals onto $\mathrm{H}-25$ medium in slant tubes and incubating at $25^{\circ} \mathrm{C}$ for 5 to 7 days.

Determination of fungicide sensitivity (concentration producing $50 \%$ growth inhibition $\left[\mathbf{E C}_{50}\right.$ values]). Conidia on 7- to 10-day-old, H-25 slant cultures were suspended in 4 to $5 \mathrm{ml}$ of sterile distilled water containing $0.01 \%$ Triton X-100, vortexed 5 to $10 \mathrm{~s}$, and filtered through double-layered cheesecloth to remove hyphal fragments. The suspension was adjusted to $10^{6}$ conidia per $\mathrm{ml}$, and $1 \mathrm{ml}$ was added to $15 \mathrm{ml}$ of molten "disk agar" (H-25 agar supplemented with agar $(6 \mathrm{~g} /$ liter $)$ to increase firmness $)$ at $50^{\circ} \mathrm{C}$, dispensed immediately into petri dishes, and incubated for $24 \mathrm{~h}$ at $25^{\circ} \mathrm{C}$. Disks were cut from these cultures with a cork borer $(4-\mathrm{mm}$ diameter), and one disk was placed in the center of each dish containing fungicide-amended or nonamended $\mathrm{H}-25$ agar $(\mathrm{pH}=5.9 \pm$ 0.2 ). Colony diameters were measured at 7 to 10 days at $25^{\circ} \mathrm{C}$. Percent inhibition at each fungicide concentration was calculated from the mean colony diameter on medium without fungicide and from the colony diameter on each fungicide-amended plate

$$
\% \text { inhibition }=\frac{\bar{X}-X_{i}}{\bar{X}} \times 100
$$

in which $\bar{X}$ is the mean colony diameter on nonamended medium (minus the 4-mm inoculum disk) and $X_{i}$ is the colony diameter on a single fungicide-amended plate (minus the 4-mm inoculum disk). A linear regression of percent inhibition versus fungicide concentration was calculated, and the fungicide concentration estimated to produce $50 \%$ inhibition $\left(\mathrm{EC}_{50}\right)$ was determined by interpolation from the regression line.

Factors affecting $\mathbf{E C}_{50}$ value. Inoculum age. The effect of inoculum age on the $\mathrm{EC}_{50}$ value was determined for triple-resistant isolates 151 and 1116 in the manner described above, except that the inoculum disks were transferred to H-25 medium amended with several concentrations of imazalil, thiabendazole, or $o$-phenylphenol (three dishes per concentration) at $0,4,8,12,16,20,24,32,40$, and $48 \mathrm{~h}$ after the disk agar was seeded with conidia. The experiment was repeated using two other triple-resistant isolates (1693 and 1750) and one wild-type isolate (M6R).

$p H$. The effect of medium $\mathrm{pH}$ on imazalil activity $\left(\mathrm{EC}_{50}\right)$ was investigated with imazalil-resistant isolate 151 on $\mathrm{H}-25$ medium nonbuffered $(\mathrm{pH} 5.9)$ and buffered at $\mathrm{pHs} 5.7,5.5$, and 5.1 with $2(\mathrm{~N}$-morpholino)ethanesulfonic acid (MES) $(0.15 \mathrm{M}) / \mathrm{NaOH}(0.1 \mathrm{M})$. The buffers contained various proportions of $\mathrm{MES} / \mathrm{NaOH}(25 / 0$, $21.1 / 3.9$, and $17.7 / 7.3 \mathrm{ml}$ ) to buffer the medium at $\mathrm{pHs} 5.1,5.5$, and 5.7 , respectively. Initial and final $\mathrm{pH}$ of the media was measured by applying a surface electrode to the surface of cooled media in petri dishes. The buffer solution $(25 \mathrm{ml})$ was mixed with $75 \mathrm{ml}$ of concentrated $(1.33 \times) \mathrm{H}-25$ medium (total volume, $100 \mathrm{ml}$ ). The imazalil concentrations in $\mathrm{H}-25$ medium at each $\mathrm{pH}$ were $0,0.25$, $0.5,0.75,1.0,1.25,1.5$, and $1.75 \mu \mathrm{g} / \mathrm{ml}$. Five replicate dishes were used at each concentration of imazalil at each $\mathrm{pH}$. The experiment was repeated.

Sensitivity of Penicillium isolates to postharvest fungicides. As described above, $\mathrm{EC}_{50}$ values were determined for imazalil-sensitive $P$. digitatum (24 isolates) and $P$. italicum (16 isolates) for imazalil, thiabendazole, and $o$-phenylphenol. Fungicide concentrations in amended $\mathrm{H}-25$ medium were $0,0.015,0.020,0.025,0.030$, $0.035,0.040,0.045$, and $0.050 \mu \mathrm{g}$ of imazalil per $\mathrm{ml} ; 0,0.1,0.5$, and $1.0 \mu \mathrm{g}$ of thiabendazole per $\mathrm{ml}$; and $0,1,5,10$, and $15 \mu \mathrm{g}$ of $o$ phenylphenol per $\mathrm{ml}$. All isolates were collected from citrus groves.

$\mathrm{EC}_{50}$ values for imazalil-resistant $P$. digitatum (54 isolates) and $P$. italicum (4 isolates), collected from citrus packinghouses, were determined in the same manner as imazalil-sensitive isolates, except that the fungicide concentrations in the medium were $0,0.3$, $0.4,0.5,0.6,0.8$, and $1.0 \mu \mathrm{g}$ of imazalil per ml; $0,10,20,30$, and $40 \mu \mathrm{g}$ of thiabendazole per $\mathrm{ml}$; and $0,5,10,20$, and $30 \mu \mathrm{g}$ of $o$ phenylphenol per $\mathrm{ml}$. The imazalil-resistant isolates of $P$. digitatum were collected in 1988, 1990, and 1996 (18 each year) and were resistant also to thiabendazole and $o$-phenylphenol. The mean $\mathrm{EC}_{50}$ values for isolates collected each year were compared by analysis of variance (ANOVA) to detect significant changes in sensitivity of $P$. digitatum to the three fungicides over time.

Imazalil concentrations used in assays with imazalil-sensitive and -resistant isolates were not replicated because $R^{2}$ values for regression lines averaged $>0.95$ and because additional concentrations of the fungicides yielded more valuable data than replicates of concentrations. However, other measures were taken to ensure the accuracy of $\mathrm{EC}_{50}$ values: each test, which included 30 isolates, was repeated and included a reference isolate. The fungicide sensitivity of the reference isolates was determined previously in five tests in which each fungicide concentration was replicated three times.

Influence of triple resistance on growth. Thirty-five isolates each of triple-resistant and imazalil-resistant (only) $P$. digitatum were used to determine if the level of resistance to imazalil differed in the two populations. A loopful of spore suspension (approximately $10^{8}$ spores per $\mathrm{ml}$ ) of each isolate was streaked onto the following H-25 media: nonamended and amended with $0.4 \mu \mathrm{g}$ of imazalil per ml. Fungal growth (presence or absence) was evaluated at 7 days at $25^{\circ} \mathrm{C}$.

\section{RESULTS}

Penicillium isolates. Conidia of 300 isolates of imazalil-resistant $P$. digitatum were collected in 26 California citrus packinghouses in 1986 to 1994 . These isolates produced typical green mold on imazalil-treated lemons and sporulated heavily on $\mathrm{H}-25$ medium amended with imazalil $(0.1 \mu \mathrm{g} / \mathrm{ml})$. In contrast, all 26 isolates of $P$. digitatum collected in citrus groves decayed, but did not sporulate on, imazalil-treated lemons and did not grow on H-25 medium amended with $0.1 \mu \mathrm{g}$ of imazalil per ml.

Imazalil-resistant $P$. italicum was relatively rare; out of 59 total isolates collected in 1994 (41 from packinghouses and 18 from groves), resistance was found at two packinghouses. A total of 
four isolates was collected. Previous work in this laboratory looked at an additional 133 isolates of $P$. italicum (58 from packinghouses and 75 from groves) collected between 1988 and 1992, and no imazalil-resistant isolates were detected (J. W. Eckert, unpublished data).

The proportion of collected isolates that were resistant to imazalil, thiabendazole, and $o$-phenylphenol increased from 43.1\% (22 out of 51) in 1988 to $77.2 \%$ (61 out of 79) in 1990 and $74.2 \%$ (46 out of 62) in 1994. All 114 thiabendazole-resistant isolates of $P$. digitatum collected from 1988 to 1994 were resistant to $o$-phenylphenol. Resistant biotypes from packinghouses fell into three groups: resistant to (i) imazalil only; (ii) thiabendazole and $o$-phenylphenol; and (iii) imazalil, thiabendazole, and $o$-phenylphenol.

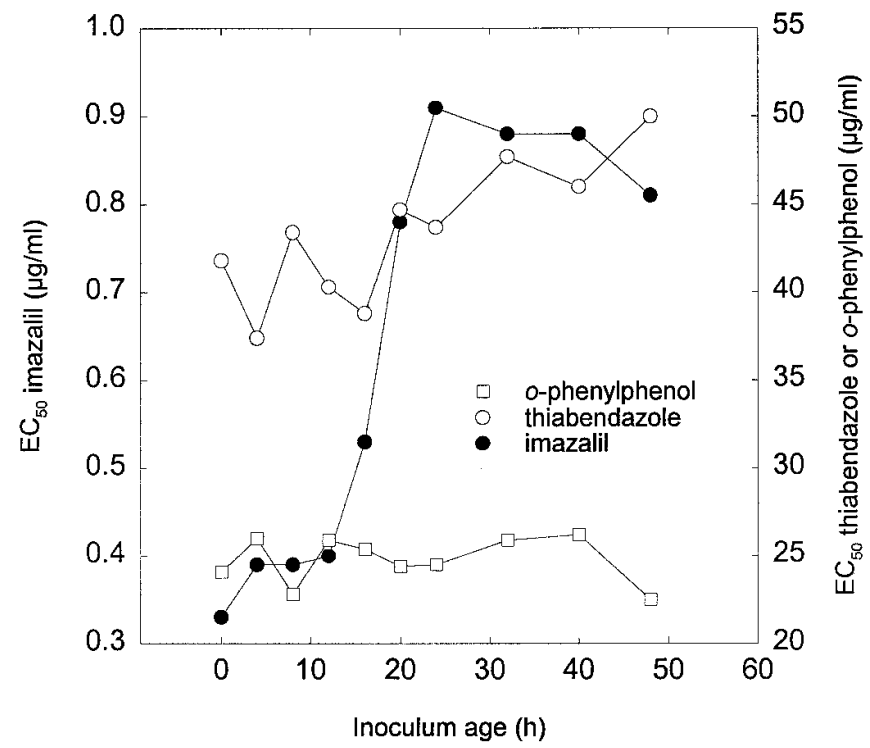

Fig. 1. Effect of inoculum age on the fungicide concentration estimated to produce $50 \%$ inhibition $\left(\mathrm{EC}_{50}\right)$ for triple-resistant Penicillium digitatum isolate 1116 to imazalil, thiabendazole, and $o$-phenylphenol.
Factors affecting $\mathbf{E C}_{50}$ value. Inoculum age. An increase in inoculum age from 12 to $24 \mathrm{~h}$ increased the imazalil $\mathrm{EC}_{50}$ for $P$. digitatum isolates 151 and 1116 over twofold (from $0.40 \mu \mathrm{g} / \mathrm{ml}$ at $12 \mathrm{~h}$ to $0.91 \mu \mathrm{g} / \mathrm{ml}$ at $24 \mathrm{~h}$ ) (Fig. 1). Two other imazalil-resistant isolates (1693 and 1750) and an imazalil-sensitive isolate (M6R) showed the same inoculum age-EC $\mathrm{E}_{50}$ relationship. The $\mathrm{EC}_{50}$ for thiabendazole for isolate 1116 increased slightly with inoculum age ( 0 to $48 \mathrm{~h}$ ), while the $\mathrm{EC}_{50}$ for $o$-phenylphenol was not significantly affected by inoculum age between 0 and $48 \mathrm{~h}$.

$p H$. The $\mathrm{EC}_{50}$ for imazalil-resistant $P$. digitatum (isolate 151) was inversely related to the $\mathrm{pH}$ of the medium (Fig. 2A). The $\mathrm{EC}_{50}$ at $\mathrm{pH} 5.7(0.88 \mu \mathrm{g} / \mathrm{ml})$ was 1.7 and $5.3 \times$ lower than the values determined at $\mathrm{pH} 5.5\left(\mathrm{EC}_{50}=1.53 \mu \mathrm{g} / \mathrm{ml}\right)$ and $\mathrm{pH} 5.1\left(\mathrm{EC}_{50}=\right.$ $4.66 \mu \mathrm{g} / \mathrm{ml})$, respectively. In the medium buffered with $\mathrm{MES} / \mathrm{NaOH}$, growth inhibition appeared to be a function of the concentration of dissociated (neutral) imazalil, because the dosage response curves for $\mathrm{pHs}$ 5.1, 5.5, and 5.7 are superimposed when growth inhibition is plotted against concentration of dissociated imazalil (Fig. 2B). A comparison of dosage-response curves for dissociated imazalil at pH 5.9 (nonbuffered) and $\mathrm{pH} 5.7$ (buffered) suggests that MES increased the activity of imazalil (Fig. 2B). Final pH of the media was \pm 0.25 units from the initial $\mathrm{pH}$.

Fungicide sensitivity. All $P$. digitatum isolates collected from citrus groves were sensitive to imazalil, thiabendazole, and $o$-phenylphenol with mean $\mathrm{EC}_{50}$ values of $0.026,0.1$, and $6.3 \mu \mathrm{g} / \mathrm{ml}$, respectively (Table 1). Mean percent inhibition of mycelial growth by thiabendazole at the lowest concentration tested $(0.1 \mu \mathrm{g} / \mathrm{ml})$ was $57.8 \pm 9.2 \%$ for 24 isolates.

Imazalil-resistant $P$. digitatum was approximately $35 \times$ more resistant to imazalil than the wild type. The level of imazalil resistance in isolates of $P$. digitatum collected from packinghouses remained relatively constant $\left(\mathrm{EC}_{50}\right.$ range $=0.87$ to $\left.0.92 \mu \mathrm{g} / \mathrm{ml}\right)$ from 1988 to 1994 (Table 2). The mean $\mathrm{EC}_{50}$ values for 1988, 1990, and 1994 were not significantly different (ANOVA; $P=0.05$ ).

Isolates of $P$. italicum collected from citrus groves were sensitive to imazalil. The mean $\mathrm{EC}_{50}$ value for 17 isolates was $0.031 \pm$ $0.009 \mu \mathrm{g}$ of imazalil per ml. Wild-type $P$. italicum was slightly less sensitive to imazalil, thiabendazole, and $o$-phenylphenol than was

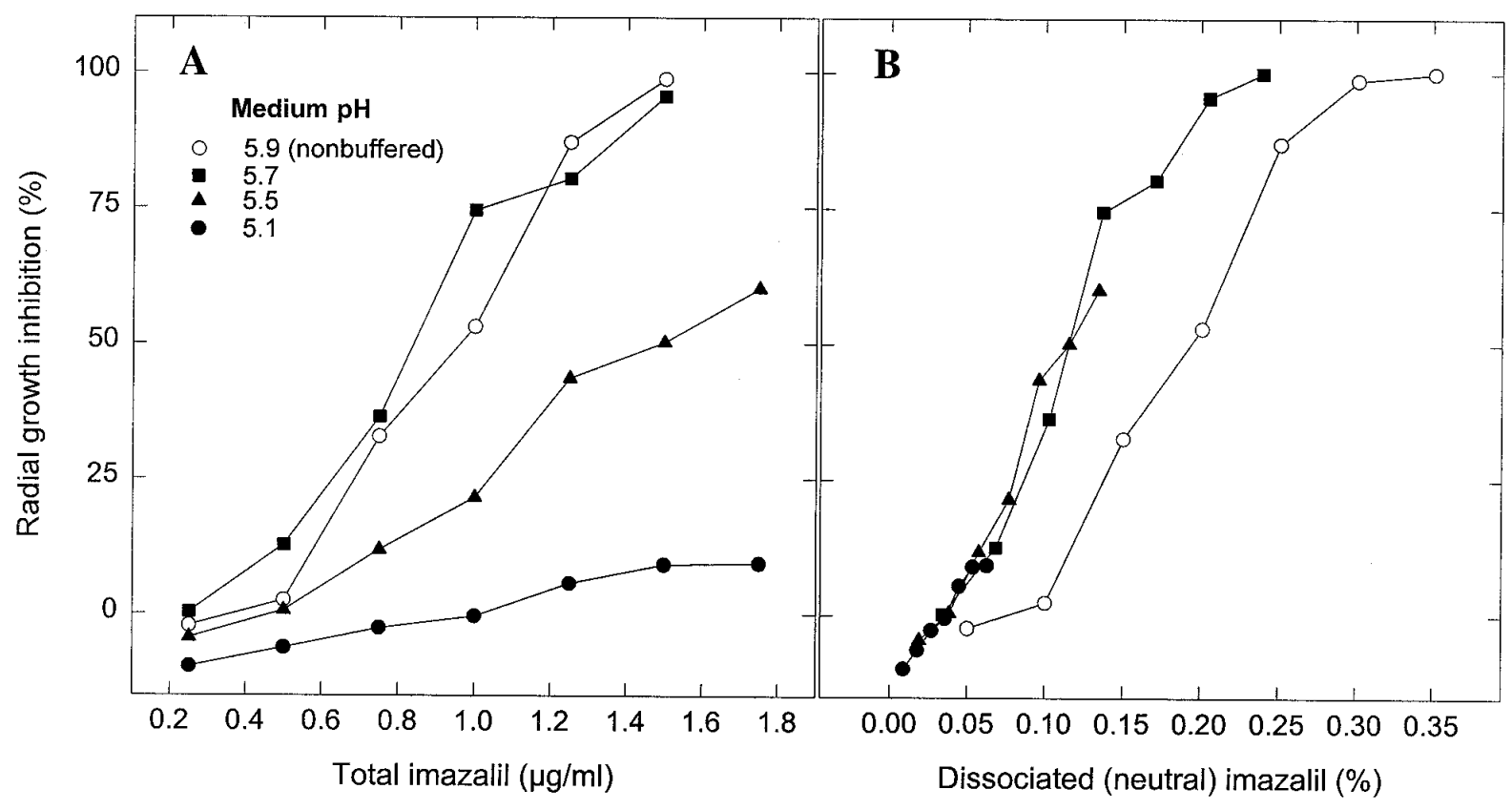

Fig. 2. A, Effect of medium $\mathrm{pH}$ on imazalil activity (inhibition of mycelial growth) against imazalil-resistant Penicillium digitatum isolate 151. B, Effect of the concentration of dissociated imazalil (calculated) on growth inhibition at the same $\mathrm{pH}$ values. Each data point represents the mean of five replicates. $\mathrm{H}-25$ medium was buffered with 2( $\mathrm{N}$-morpholino)ethanesulfonic acid/ $\mathrm{NaOH}$ to give the desired $\mathrm{pH}$. The colony diameter was measured at 6 days.

$\%$ dissociated imazalil $=\left[\frac{100}{1+10^{\left(\mathrm{pH}^{\left.-\mathrm{pK}_{\mathrm{a}}\right)}\right.}}\right]-100$ (1). Imazalil $\mathrm{pK}_{\mathrm{a}}=6.53$ (29). 
wild-type $P$. digitatum. Four imazalil-resistant isolates of $P$. italicum were isolated from two packinghouses in 1994. The mean $\mathrm{EC}_{50}$ value for these isolates was $0.52 \pm 0.08 \mu \mathrm{g}$ of imazalil per ml, approximately half the mean $\mathrm{EC}_{50}$ value for imazalil-resistant biotypes of $P$. digitatum (Table 2).

Cost of triple resistance. Thirty-five isolates that were resistant only to imazalil produced colonies from conidia streaked on $\mathrm{H}-25$ medium containing $0.4 \mu \mathrm{g}$ of imazalil per $\mathrm{ml}$, whereas colony development of 35 triple-resistant isolates was inhibited completely on the same medium.

\section{DISCUSSION}

Intensive postharvest use of the chemically unrelated fungicides imazalil, thiabendazole, and $o$-phenylphenol on citrus fruits in California has resulted in the proliferation of triple-resistant biotypes of $P$. digitatum. However, this did not lead to an increase in the level of resistance $\left(\mathrm{EC}_{50}\right)$ to any of the fungicides in isolates collected between 1988 and 1994. Furthermore, none of the isolates collected during that period possessed a significantly higher level of resistance than our original imazalil-resistant isolates collected in 1986.

Concern over imazalil resistance prompted packinghouse service companies to combine imazalil and thiabendazole in their fruit coating formulations. Theoretical studies of resistance development have revealed that the combination of two selective fungicides to combat resistance is a reasonable strategy only when used against wild populations of the pathogen with an extremely low frequency of resistance to both fungicides (28). Even then, sequential use of two unrelated fungicides may be a more effective strategy. When the combination strategy was implemented in California, the population of Penicillium spp. in packinghouses was well endowed with independent resistance genes for imazalil, thiabendazole, and $o$ phenylphenol. Treatment of fruit with all of these fungicides provided a substrate that selected for mutant biotypes possessing genes for resistance to each of the fungicides. Furthermore, laboratory experiments suggest that multiple-resistant biotypes could be sustained in the pathogen population, at least in the short term, by application of only one of the fungicides (12). In our survey, the proportion of triple-resistant isolates in the $P$. digitatum population in packinghouses increased from 43\% in 1988 to over $70 \%$ by 1994 .

Resistance to imazalil and other demethylation inhibitors (DMI) is controlled by a polygenic system in certain fungi $(21,33)$, and the development of resistance in $P$. expansum (34) and P. italicum $(7,8)$ suggests that several minor genes control imazalil resistance in these species as well. Surveys of wild populations of Penicillium spp. $(2,7,25)$ revealed biotypes with varying degrees of sensitivity to imazalil, but none were resistant to dosages recommended for disease control. Likewise, we have never isolated a $P$. digitatum isolate from a citrus grove that was capable of growing

TABLE 1. Sensitivity of wild-type citrus grove isolates of Penicillium digitatum and $P$. italicum to imazalil, thiabendazole, and $o$-phenylphenol

\begin{tabular}{|c|c|c|c|}
\hline Fungicide, species & Mean $\mathrm{EC}_{50}{ }^{\mathrm{w}}$ & Mean $\%$ inhibition & $n^{\mathrm{x}}$ \\
\hline \multicolumn{4}{|l|}{ Imazalil } \\
\hline P. digitatum & $0.026 \pm 0.003^{\mathrm{y}}$ & $\ldots$ & 24 \\
\hline P. italicum & $0.031 \pm 0.009$ & $\ldots$ & 17 \\
\hline \multicolumn{4}{|l|}{$o$-Phenylphenol } \\
\hline P. digitatum & $6.3 \pm 1.0$ & $\ldots$ & 28 \\
\hline P. italicum & $6.8 \pm 1.2$ & $\ldots$ & 16 \\
\hline \multicolumn{4}{|l|}{ Thiabendazole $^{\mathrm{z}}$} \\
\hline P. digitatum & $\ldots$ & $57.8 \pm 9.2$ & 24 \\
\hline P. italicum & $\ldots$ & $35.1 \pm 7.8$ & 16 \\
\hline
\end{tabular}

${ }^{\mathrm{w}}$ Fungicide concentration estimated to produce $50 \%$ inhibition.

${ }^{x}$ Number of isolates tested.

${ }^{y}$ Values are means of multiple isolates from a single experiment followed by the standard deviation of the mean.

${ }^{\mathrm{z}} 0.1 \mu \mathrm{g} / \mathrm{ml}$. on PDA with $0.1 \mathrm{ppm}$ of imazalil or of sporulating on lemons dipped in a 1,000-ppm imazalil solution.

de Waard et al. $(7,8)$ demonstrated a stepwise progression in imazalil resistance in $P$. italicum by repeated mass selection on increasing concentrations of imazalil in the culture medium. A biotype that resulted from five selection steps was not well controlled on oranges dipped in a 500-ppm imazalil solution. de Waard and van Nistelrooy (8) suggested that this biotype may have accumulated at least five minor genes for imazalil resistance and these genes interacted in an additive fashion to confer a significant level of resistance to this fungicide. One additional selection step resulted in a biotype with a higher level of resistance, but it was not stable in the absence of imazalil.

Biotypes of $P$. digitatum and $P$. italicum with a moderate level of imazalil resistance are virulent and stable in the absence of imazalil $(8,19)$. They are more fit than wild isolates on imazaliltreated fruit, but most of these resistant biotypes are less competitive than wild biotypes on nontreated fruit, and their frequency decreases in the spore population over several disease cycles $(7,8,19)$. However, fitness of resistant biotypes could improve with time if selection pressure continues. Biotypes of $P$. italicum with high levels of imazalil resistance, produced with mutagenizing agents, tend to have reduced virulence, saprophytic fitness, and sporulation capacity $(7,8,33)$. Such observations nurtured the speculation that resistance to imazalil and other DMIs was not likely to become a practical problem in disease control $(5,32)$.

Our observation that the degree of imazalil resistance in isolates of $P$. digitatum did not increase significantly from 1986 to 1994 may be explained by the relatively constant selection pressure produced by the standard treatment of $2,000 \mathrm{ppm}$ of imazalil incorporated in a fruit coating formulation. The resistant biotypes that evolved under this degree of selection pressure are as virulent as wild types and more fit on imazalil-treated citrus fruits (19). Therefore, they have become the dominant biotypes of $P$. digitatum in California packinghouses that routinely store imazalil-treated fruit. While natural mutants with greater resistance to imazalil are possible, they probably would be burdened with diminished virulence, sporulation, and competitive fitness $(7,8,13,14,23,30,34)$. They would have no evolutionary advantage over prevailing resistant biotypes that are not controlled by the standard imazalil spray treatment. However, increasing the effectiveness of imazalil by using a different method of application (e.g., heated aqueous solution instead of wax) may alter this situation (31).

The increase in the proportion of triple-resistant biotypes in the P. digitatum population in California packinghouses from 1988 to 1994 may be attributed to the selection of independent mutant genes in individual biotypes subjected to continuous selection pressure of the three fungicides applied to the same fruit.

Imazalil, like other DMIs, is considered a low- to medium-risk fungicide with respect to the probability that a practical resistance problem will develop $(14,23)$. Similar imazalil-resistant isolates of $P$. digitatum and $P$. italicum have been isolated in Rotterdam from citrus fruits produced in Spain and Israel $(3,4)$. Imazalil-resistant

TABLE 2. Sensitivity of 54 triple-resistant isolates (18 each in 1988, 1990, and 1994) of Penicillium digitatum to imazalil, thiabendazole, and $o$-phenylphenol ${ }^{\mathrm{X}}$

\begin{tabular}{lccc}
\hline & \multicolumn{3}{c}{ Mean EC $_{50}(\mu \mathrm{g} / \mathrm{ml})^{\mathrm{y}}$} \\
\cline { 2 - 4 } Year & Imazalil & Thiabendazole & $o$-Phenylphenol \\
\hline 1988 & $0.88 \pm 0.17 \mathrm{a}^{\mathrm{z}}$ & $49.83 \pm 6.20 \mathrm{a}$ & $37.74 \pm 6.64 \mathrm{a}$ \\
1990 & $0.92 \pm 0.09 \mathrm{a}$ & $47.84 \pm 8.94 \mathrm{a}$ & $36.82 \pm 6.83 \mathrm{a}$ \\
1994 & $0.87 \pm 0.18 \mathrm{a}$ & $47.12 \pm 9.35 \mathrm{a}$ & $34.63 \pm 6.59 \mathrm{a}$ \\
\hline
\end{tabular}

$x$ All isolates were collected in California citrus packinghouses.

${ }^{y}$ Fungicide concentration estimated to produce 50\% inhibition. Values are means of multiple isolates from a single experiment followed by the standard deviation of the mean.

${ }^{z}$ Values within columns followed by the same letter are not significantly different $(P=0.05)$. 
isolates have not been reported in Florida (2). The 5-year lag period between the introduction of imazalil into commercial California packinghouses and the isolation of resistant isolates of $P$. digitatum may support the hypothesis that imazalil resistance in Penicillium spp. is controlled by a polygenic system and several minor genes for resistance must be accumulated for a practical level of resistance to this fungicide to develop $(7,8,14,30)$. However, field isolates with intermediate levels of resistance have not been found. Thiabendazole resistance, due to a single major gene mutation (6,34), appeared in P. italicum isolates in California lemon packinghouses after only 15 months of continuous use of this fungicide (17).

$P$. digitatum isolates that were resistant only to imazalil had a higher level of imazalil resistance than isolates resistant to imazalil, $o$-phenylphenol, and thiabendazole. The two groups of imazalilresistant isolates were discriminated by streaking spore suspensions of both groups of isolates onto $\mathrm{H}-25$ medium amended with $0.4 \mu \mathrm{g}$ of imazalil per $\mathrm{ml}$ and $1.0 \mu \mathrm{g}$ of thiabendazole per $\mathrm{ml}$. The triple-resistant isolates did not form colonies on the imazalilamended medium, whereas isolates resistant to imazalil only did form colonies. The increased imazalil sensitivity of the triple-resistant isolates appears to be expressed in the early stages of conidial development, because there was no apparent difference in sensitivity expressed in our $\mathrm{EC}_{50}$ and $\mathrm{EC}_{90}$ values. Guan et al. (15) reported that conidial germination in $P$. italicum was more sensitive to imazalil than was mycelial growth of hyphae approximately $18 \mathrm{~h}$ old. The hyphal inoculum for our $\mathrm{EC}_{50}$ studies was approximately $24 \mathrm{~h}$ old. This difference may account for the difference between the two assays.

Variability in the $\mathrm{EC}_{50}$ values reported for imazalil by various researchers can be explained by differences in experimental procedures and the calculation of the $\mathrm{EC}_{50}$ values. We observed that $\mathrm{pH}$ of the culture medium and inoculum age have a significant effect upon the $\mathrm{EC}_{50}$ value. The $\mathrm{pK}_{\mathrm{a}}$ of imazalil, 6.53 (29), is sufficiently close to the $\mathrm{pH}$ of PDA $(5.6 \pm 0.2)$ and $\mathrm{H}-25$ medium $(5.9 \pm 0.2)$ that a slight difference in the $\mathrm{pH}$ of the culture medium in different assays could have a significant effect on the concentration of the neutral (dissociated) form of imazalil, which is largely responsible for the antifungal activity of this compound $(15,29)$. At $\mathrm{pH} 5.5,9.1 \%$ of the imazalil in the culture medium is in the neutral (active) form; at $\mathrm{pH} 6.0,24 \%$ of the imazalil is in the neutral form (1). The striking effect of $\mathrm{pH}$ upon the $\mathrm{EC}_{50}$ value is shown in Figure 2. To minimize the effect of $\mathrm{pH}$ on $\mathrm{EC}_{50}$ values, all petri dishes in a single 30-isolate test contained the same batch of $\mathrm{H}-25$ medium (pH $5.9 \pm 0.2$ ) and included a well-characterized isolate of a Penicillium sp. as a reference.

The striking effect of inoculum age upon the $\mathrm{EC}_{50}$ value for imazalil, but not for thiabendazole or $o$-phenylphenol, may be due to cell permeability to the fungicide or to action sites unique to different stages of fungal growth. Guan et al. (15) noted that conidial germination was more sensitive to imazalil than was the growth of 18-h-old hyphae. The mass of fungus tissue interacting with a relatively low concentration of imazalil in the culture medium may also be a factor, since the estimate of minimum inhibitory concentrations (MICs) can be influenced by the mass of fungal inoculum (J. W. Eckert, unpublished data).

In our experiments, the dose response of $P$. digitatum and $P$. italicum to imazalil at the concentrations tested was linear, with $R^{2}$ values generally greater than 0.95 . The calculation of $\mathrm{EC}_{50}$ values using the original experimental units was simpler and provided more accurate estimates of $\mathrm{EC}_{50}$ values than the log-dose probit transformation.

de Waard et al. (8) reported the imazalil sensitivity of a single wildtype $P$. italicum isolate $\left(\mathrm{EC}_{50}=0.07 \mu \mathrm{g} / \mathrm{ml}\right)$ and of several laboratoryinduced imazalil-resistant mutants. The $\mathrm{EC}_{50}$ for their wild-type $P$. italicum was more than twice the mean of 17 wild-type isolates that we tested (mean $\mathrm{EC}_{50}=0.031 \mu \mathrm{g} / \mathrm{ml}$ ). This difference in imazalil sensitivity is easily within the error range of the assay procedure.
The scarcity of imazalil-resistant isolates of $P$. italicum $(4,8,19$, 22 ) in the packinghouse is puzzling. Abundance of the species in citrus groves ensures that it is continually introduced to the packinghouse environment, where there is intense selection pressure for fungicide resistance. The existence of a few stable, virulent, imazalil-resistant isolates of $P$. italicum that have been characterized by us and several other investigators $(3,4,7,8)$ suggests that significant populations of the species should develop under the selection pressure of this fungicide. However, this has not occurred under field conditions, which suggests a fundamental difference in the biology of $P$. italicum and $P$. digitatum. This difference could result from factors such as smaller populations of $P$. italicum in packinghouses available for selection, greater imazalil sensitivity of resistant mutants, and the lower parasitic fitness and reproductive capacity of this species compared with $P$. digitatum (20). A better understanding of the biology and ecology of $P$. digitatum and $P$. italicum may offer important insight into the management of fungicide resistance in citrus green mold and other diseases.

\section{ACKNOWLEDGMENTS}

We thank the California Citrus Research Board for financial support and M. Ratnayake for assistance with fungicide sensitivity assays.

\section{LITERATURE CITED}

1. Albert, A. 1985. Some numerical assistance. Pages 641-657 in: Selective Toxicity, the Physico-Chemical Basis of Therapy. 7th ed. Chapman \& Hall, New York.

2. Brown, G. E. 1989. Baseline sensitivity of Florida isolates of Penicillium digitatum to imazalil. Plant Dis. 73:773-774.

3. Bus, V. G. 1992. $\mathrm{ED}_{50}$ levels of Penicillium digitatum and P. italicum with reduced sensitivity to thiabendazole, benomyl and imazalil. Postharvest Biol. Technol. 1:305-315.

4. Bus, V. G., Bongers, A. J., and Risse, L. A. 1991. Occurrence of Penicillium digitatum and $P$. italicum resistant to benomyl, thiabendazole, and imazalil on citrus fruit from different geographic origins. Plant Dis. 75: 1098-1100.

5. Davé, B., Sales, M., and Walia, M. 1989. Resistance of different strains of Penicillium digitatum to imazalil treatment in California citrus packinghouses. Proc. Fla. State Hortic. Soc. 102:178-179.

6. Davidse, L. C., and Flach, W. 1978. Interaction of thiabendazole with fungal tubulin. Biochim. Biophys. Acta 543:82-90.

7. de Waard, M. A., Groeneweg, H., and van Nistelrooy, J. G. M. 1982. Laboratory resistance to fungicides which inhibit ergosterol biosynthesis in Penicillium italicum. Neth. J. Plant Pathol. 88:99-112.

8. de Waard, M. A., and van Nistelrooy, J. G. M. 1990. Stepwise development of laboratory resistance to DMI-fungicides in Penicillium italicum. Neth. J. Plant Pathol. 96:321-329.

9. Díaz Borrás, M. A., Vila Aguilar, R., and Hernández Giménez, E. 1987. Resistance to $o$-phenylphenol, benomyl, TBZ and CGA-64251 in strains of Penicillium digitatum isolated from Spanish citrus packinghouses. Rev. Agroquím. Tecnol. Aliment. 27:439-445.

10. Eckert, J. W. 1987. Penicillium digitatum biotypes with reduced sensitivity to imazalil. (Abstr.) Phytopathology 77:1728.

11. Eckert, J. W., Sievert, J. R., and Ratnayake, M. 1994. Reduction of imazalil effectiveness against citrus green mold in California packinghouses by resistant biotypes of Penicillium digitatum. Plant Dis. 78:971-974.

12. Eckert, J. W., and Wild, B. L. 1983. Problems of fungicide resistance in Penicillium rot of citrus fruits. Pages 525-556 in: Pest Resistance to Pesticides. G. P. Georghiou and T. Saito. eds. Plenum Publishing Corp., New York.

13. Fuchs, A., and Drandarevski, C. A. 1976. The likelihood of development of resistance to systemic fungicides which inhibit ergosterol biosynthesis. Neth. J. Plant Pathol. 82:85-87.

14. Georgopoulos, S. G., and Skylakakis, G. 1986. Genetic variability in the fungi and the problem of fungicide resistance. Crop Prot. 5:299-305.

15. Guan, J., Kerkenaar, A., and de Waard, M. A. 1989. Effects of imazalil on sterol composition of sensitive and DMI-resistant isolates of Penicillium italicum. Neth. J. Plant Pathol. 95(suppl. 1):73-86.

16. Harding, Jr., P. R. 1962. Differential sensitivity to sodium orthophenylphenate by biphenyl-sensitive and biphenyl-resistant strains of Penicillium digitatum. Plant Dis. Rep. 46:100-104.

17. Harding, Jr., P. R. 1972. Differential sensitivity to thiabendazole by strains of Penicillium italicum and P. digitatum. Plant Dis. Rep. 56:256-260. 
18. Harding, Jr., P. R. 1976. R 23979, a new imidazole derivative effective against postharvest decay of citrus by molds resistant to thiabendazole, benomyl, and 2-aminobutane. Plant Dis. Rep. 60:643-646.

19. Holmes, G. J., and Eckert, J. W. 1995. Relative fitness of imazalil-resistant and -sensitive biotypes of Penicillium digitatum. Plant Dis. 79:1068-1073.

20. Holmes, G. J., Eckert, J. W., and Pitt, J. I. 1994. Revised description of Penicillium ulaiense and its role as a pathogen of citrus fruit. Phytopathology 84:719-727.

21. Kalamarakis, A. E., Ziogas, B. N., and Georgopoulos, S. G. 1987. Resistance to ergosterol biosynthesis inhibitors in Nectria haematococca var. cucurbitae. Chem. Control Newsl. 8:18-19.

22. Kaplan, H. J., and Davé, B. A. 1979. The current status of imazalil. Proc. Fla. State Hortic. Soc. 92:37-43.

23. Köller, W., and Scheinpflug, H. 1987. Fungal resistance to sterol biosynthesis inhibitors: A new challenge. Plant Dis. 71:1066-1074.

24. Kuramoto, T. 1976. Resistance to benomyl and thiophanate-methyl in strains of Penicillium digitatum and P. italicum in Japan. Plant Dis. Rep. 60:168-172.

25. Penrose, L. J. 1993. Baseline sensitivities of preserved isolates of Penicillium spp. from pome fruit to imazalil and iprodione. Australas. Plant Pathol. 22:37-38.

26. Perkins, D. D. 1962. Preservation of Neurospora stock cultures with anhydrous silica gel. Can. J. Microbiol. 8:591-594.

27. Rebellato, L. H., and Monteiro, M. C. 1984. Report of an imazalil resistant strain of Penicillium digitatum (Sacc) in citrus in Uruguay. Proc. Int.
Soc. Citric. 1:588-590.

28. Shaw, M. W. 1993. Theoretical analysis of the effect of interacting activities on the rate of selection for combined resistance to fungicide mixtures. Crop Prot. 12:120-125.

29. Siegel, M. R., Kerkenaar, A., and Sijpesteign, A. K. 1977. Antifungal activity of the systemic fungicide imazalil. Neth. J. Plant Pathol. 83(suppl. 1): 121-133.

30. Skylakakis, G. 1987. Changes in the composition of pathogen populations caused by resistance to fungicides. Pages 227-237 in: Populations of Plant Pathogens, Their Dynamics and Genetics. M. S. Wolfe and C. E. Caten, eds. Blackwell Science Publications, Palo Alto, CA.

31. Smilanick, J. L., Michael, E. F., Mansour, M. F., Mackey, B. E., Margosan, D. A., Flores, D., and Weist, C. F. 1997. Improved control of green mold of citrus with imazalil in warm water compared with its use in wax. Plant Dis. 81:1299-1304.

32. van Gestel, J. 1988. Imazalil-sensitive and less sensitive strains of Penicillium digitatum: Competition experiments on oranges. Proc. 6th Int. Citrus Congr. 3:1511-1514.

33. van Tuyl, J. M. 1977. Genetic aspects of resistance to imazalil in Aspergillus nidulans. Neth. J. Plant Pathol. 83(suppl. 1):169-176.

34. van Tuyl, J. M. 1977. Genetics of fungal resistance to systemic fungicides. Ph.D. thesis. Agricultural University, Wageningen, the Netherlands.

35. Wild, B. L. 1994. Differential sensitivity of citrus green mould isolates (Penicillium digitatum Sacc.) to the fungicide imazalil. N.Z. J. Crop Hortic. Sci. 22:167-171. 